\title{
A oralidade, a escrita e as condições de produção de textos na escola: a constituição da escrita escolar em objeto de investigações acadêmicas
}

\author{
Émerson de Pietri"
}

\section{Resumo}

No presente trabalho, tematiza-se o processo de constituição da escrita escolar em objeto de pesquisa de investigaçôes acadêmicas. $\mathrm{O}$ material de análise foi produzido em programas de pós-graduação de universidades brasileiras. Observaram-se as bases semânticas dos discursos sobre ensino de Língua Portuguesa que se constituíram na década de 80 do século XX. Os trabalhos de pesquisa desenvolvidos nesse momento se caracterizariam por considerar a organização textual do escrito, produzido em contexto de ensino, em função de oposiçóes resultantes de diferenças linguísticas e/ou sociais. Tais diferenças se representariam pela contraposição entre fatos de oralidade e fatos de escrita. As características dos textos produzidos na escola decorreriam, de um lado, de os alunos não terem conhecimentos sobre a modalidade escrita e, de outro, de as condiçóes de produçáo do texto na escola não serem autênticas. No tratamento em contraste de elementos associados a condiçóes internas e a condiçóes externas à escola, os fatores de textualidade se posicionam como índices discursivos para o pesquisador em seu trabalho de constituição da escrita escolar em objeto de análise.

Palavras-chave: Linguagem e Educação. Escrita. Análise do Discurso.

\footnotetext{
* Doutor em Lingüística Aplicada ao Ensino/Aprendizagem de Língua Materna, pela Universidade Estadual de Campinas (UNICAMP). Professor da Faculdade de Educação da Universidade de São Paulo (USP).
} 


\section{Introdução}

Os primeiros movimentos realizados por pesquisadores da linguagem no sentido de constituir, em material de análise, redaçôes produzidas em contexto de vestibular se realizaram nos anos finais da década de 70 do século XX (PIETRI, 2007), no Brasil. Nesse momento, a oralidade teria assumido novo status nas propostas de ensino de Língua Portuguesa na escola, quando mesmo a disciplina de Lingua Portuguesa teria sido compreendida (ao menos por autores de materiais didáticos) em novas bases, com o privilégio da comunicação e da expressão (SOARES, 2002, VENTURI; GATTI JR., 2004)1․ O texto produzido em situação escolar se tornou, então, matéria de interesse de diferentes instâncias, segundo questôes de ordem pedagógica, acadêmica e/ou oficial, num conjunto de relaçóes que fundamentaram a constituição da escrita escolar em objeto de investigaçóes acadêmicas.

A análise dos modos como a escrita escolar se constituiu em objeto de pesquisa nos anos finais da década de 1970 evidencia que um elemento comum às investigaçôes desenvolvidas então foi a consideração de que os problemas encontrados nas redaçóes escolares constituiriam sintomas de uma situação geral sobre as condiçôes do ensino e da aprendizagem nas escolas brasileiras. A referência a uma suposta crise na linguagem funcionou como elemento discursivo em que se sustentou a própria possibilidade da investigaçáo, pois indicava um ponto de partida para o trabalho investigativo, uma vez que se faria necessário, com base em tal diagnóstico, buscar suas causas, recorrendo-se, então, a subsídios teóricos para a realização do trabalho de produção e análise dos dados.

As causas apontadas para os problemas de escrita são percebidas segundo estejam ou no interior da escola, quando se consideram as condiçôes históricas de produção dos textos e o tipo de relação do sujeito com as condiçôes em que se encontra (no caso, marcado pela passividade); ou no exterior da escola, quando as referidas causas são atribuídas à sociedade de massas, à indústria cultural, e à funçâo social, política e ideológica da escola numa sociedade de classes.

O movimento do pesquisador entre um e outro desses dois polos possibilitou o acesso, ora a teorias explicativas fundadas em recursos teóricos da Psicologia (para considerar as condiçóes do sujeito), ora aos estudos sociológicos e culturais (para pensar sobre as condiçôes mais amplas em que se inserem a escola e o aluno). No realizar desse movimento entre um polo e outro - do subjetivo e do social -, tornou-se possível, portanto, a apropriação de recursos para a 
constituição da escrita escolar em objeto de análise, num momento em que não se encontravam elaboradas suficientemente bases teóricas linguísticas adequadas ao tratamento da linguagem em sua modalidade escrita (PIETRI, 2012).

No presente trabalho ${ }^{2}$, observa-se a continuidade do processo de constituição da redação escolar em objeto de pesquisa de dissertaçóes e teses, em programas de pós-graduação de universidades brasileiras, procurando-se caracterizar a (re)ordenação das bases semânticas dos discursos sobre ensino de Língua Portuguesa que se operaram na década de 80 do século XX, consideradas as diferenças que se percebem em relação à década anterior, e seus modos específicos de configuração de temas, conceitos, estratégias teóricas e objetos ${ }^{1}$.

Compóem o corpus de análise dissertaçôes de mestrado e teses de doutorado que possuem como objeto de investigação o texto escrito produzido em contexto escolar de Ensino Básico, compreendendo o período entre a $5^{a}$ série do Ensino Fundamental e o $3^{\circ}$ ano do Ensino Médio, na antiga nomenclatura. Excluíram-se, assim, pesquisas sobre escrita escolar voltadas para o ensino de caráter supletivo ou em nível de 3o grau. Decidiu-se restringir a coleta do material de análise aos programas de pós-graduação do Estado de São Paulo, na tentativa de obter maior organicidade na composiçăo do corpus em si, consideradas as relaçôes do discurso acadêmico com o oficial e o pedagógico: no momento histórico em questão, houve um importante movimento de produção e publicação, por instâncias oficiais responsáveis pela Educação no referido Estado, de documentos de referência para o ensino (Propostas e Guias Curriculares, e Subsídios a eles).

Uma vez que se trata de observar relaçóes entre discursos, a noção de interdiscurso, tal como elaborada por Maingueneau (2005), é um ponto de partida interessante para o tratamento a ser realizado do material de análise do presente estudo. Segundo a concepção proposta pelo autor, a interdiscursividade consiste no trabalho de discurso(s) sobre discurso(s), num processo de delimitação recíproca. Nesse processo, os enunciados de um discurso se constituem com base em regras semânticas específicas, que definem seu pertencimento a esse dado discurso, regras que definem também enunciados que lhe são estranhos. Concebido esse sistema de restriçóes semânticas como um modelo de competência discursiva, considera-se que os enunciadores de um discurso dado apresentam o "[...] domínio tácito de regras que permitem produzir e interpretar enunciados que resultam de sua própria formação discursiva e, correlativamente, permitem identificar como incompatíveis com 
ela os enunciados das formaçōes discursivas antagonistas" (MAINGUENEAU, 2005 , p. 23). Considera-se, assim, como unidade de análise não o discurso (entendido como "dispersão de textos cujo modo de inscrição histórica permite definir como um espaço de regularidades enunciativas"), mas um espaço de trocas entre vários discursos convenientemente escolhidos, o que supóe, portanto, a precedência do interdiscurso sobre o discurso.

Segundo Maingueneau (2005, p. 22), “[...] o caráter 'global' dessa semântica se manifesta pelo fato de que ela restringe simultaneamente o conjunto dos 'planos' discursivos: tanto o vocabulário quanto os temas tratados, a intertextualidade ou as instâncias de enunciação [...]". Nesse sentido, trabalhase com a hipótese de que a determinados discursos correspondem estruturaçóes textuais específicas, isto é, que os gêneros textuais estão em concordância com a semântica de uma dada formação discursiva. Assim, a observação dos modos como se compóe materialmente o discurso constituiria um meio para a caracterização do(s) discurso(s) em que o(s) texto(s) se inscreve $(m)$.

Parte-se da proposta de Adam (2008), fundamentada em Maingueneau (1995), quanto ao fato de o texto trazer em si índices das condiçóes de enunciação em que se produziu. A referência constituída com base nesses índices garante a definição de um espaço e de um tempo para os dizeres e, com isso, a possibilidade de movimento dos sujeitos para a configuração dos objetos de discurso. Assim, podem ser colocadas as seguintes questóes: de que modos se constituíram as condições de enunciação num dado momento histórico? Como se estabeleceram índices de pessoa, funçôes e relaçóes de tempo e espaço nessas condiçōes? Que posiçóes de sujeito foram projetadas e que objetos se produziram com seu (das condiçốes de enunciação) funcionamento?

O trabalho de análise, na presente investigação, se volta, portanto, para os modos como os sujeitos se movimentam em relação a determinados índices de tempo, de espaço e de pessoa, e como operam recortes e apropriaçôes, com esse movimento, de perspectivas teóricas diversas.

A hipótese com que se trabalha na presente investigação é a de que as pesquisas sobre escrita escolar desenvolvidas no momento histórico observado se caracterizam por considerar em contraste a relação entre fatores internos e externos à escolarização, num movimento em que se associaram, aos primeiros, os fatos de oralidade, e aos segundos, os elementos da escrita. A tematização das relaçóes da escola com seu exterior teria possibilitado, assim, a constituição da escrita escolar em objeto de pesquisa. No período observado, o dispositivo 
que sustenta o movimento analítico se fundamenta entre posiçóes marcadas em pares opositivos, como o par/oralidade x escrita/ (que se relaciona ao par / diferença linguística x norma linguística/), que se associa, por sua vez, a outro par opositivo, baseado na contraposição /condiçóes de produçáo intraescolares x condiçôes de produção extraescolares/.

Os dados a serem analisados neste momento são produzidos, portanto, com base na observação dos princípios de ordenação da situação enunciativa acima referidos (a relação oralidade-escrita e a questão da normatização linguística, associadas às considerações sobre as condições intra e extraescolares de produção do texto). Com o objetivo de manter em perspectiva a série histórica, as consideraçóes realizadas a partir dos trabalhos analisados serão apresentadas respeitando-se a sequência temporal de suas publicaçôes.

\section{A relação oralidade-escrita e a delimitação entre o extra e o intraescolar}

Um dos fatores que compóem a organização discursiva própria ao momento histórico estudado é a distinção entre as modalidades oral e escrita, que se associa a discussôes sobre variação e normatização linguística e suas relaçóes com questóes gramaticais ou discursivas. Oralidade e escrita constituem, assim, índices que referenciam lugares e tempos diversos, ocupados de modos distintos pelos sujeitos em seu trabalho para a construção de objetos de discurso. As diferenças entre as modalidades referenciam as delimitaçóes que se estabelecem com base em características sociais, econômicas e linguísticas, as quais se associam segundo graus e modos diversos nos trabalhos observados. Essas referências se relacionam com a delimitação entre o extra e o intraescolar, e com os elementos que compóem a textualidade.

Nesse sentido, no trabalho de Almeida (1980) são apresentadas semelhanças e diferenças entre as produçôes de linguagem de classes sociais distintas em função dos aspectos referentes ao monitoramento estilístico próprio a cada uma das modalidades. A autora propóe-se "[...] verificar se a coesão em textos escritos e orais produzidos por pré-adolescentes está em relação com a diferença entre língua escrita e falada e com fatores extralinguísticos, como sexo e classe social" (ALMEIDA, 1980, p. 1). O objetivo seria o de encontrar diferenças entre linguagem oral e escrita em relação aos aspectos referentes à coesão textual. Tais diferenças seriam percebidas com a quantificação e 
comparação de "[...] mecanismos de coesão usados em um estilo coloquial e um estilo mais cuidado como é a escrita" (ALMEIDA, 1980, p. 10). À oposiçâa, na pesquisa, entre linguagem oral e linguagem escrita, corresponderia a oposição entre estilo informal e estilo cuidado, e ambos os grupos de informantes teriam apresentado "uma padronização" quanto à escrita (ALMEIDA, 1980, p. 118) no que se refere ao uso de mecanismos de coesão textual.

Movimento semelhante ao de Almeida (1980) se encontra no trabalho de Bastos (1984), em que se observam questóes referentes à coerência textual em face dos modos de interlocução, considerando-se o que a autora denominou envolvimento do aluno com o texto, o que seria determinado pela situação de produção do texto. Em seu trabalho, Bastos (1984) analisa narraçóes produzidas por alunos de $2^{a}$ série do então $2^{\circ}$ Grau com o objetivo de encontrar explicaçóes para os problemas encontrados nas redaçóes escolares. A fundamentação teórica para a análise baseia-se, segundo a autora, "[...] principalmente em dois conceitos que tratam da organização textual” (BASTOS, 1984, p. VII): os conceitos de coesão e de coerência textual. Os problemas encontrados nas redaçóes analisadas seriam associados, à primeira vista, à incapacidade para o uso da língua-padrão; porém, é feita a ressalva de que se trataria, de fato, de uma questão de "manejo da escrita": "[...] a manipulação da escrita é que é precária, e esse fenômeno é confundido muitas vezes com o uso de linguagem não-padrão ou com questôes de formalidade ou informalidade de linguagem" (BASTOS, 1984, p. 95).

Bastos (1984) aponta para a "[...] necessidade de se colocar a distinção 'língua oral X língua escrita', na escola, também no nível do texto", distinguindo "[...] texto oral e escrito e as suas peculiaridades quanto à COESÃO e COERÊNCIA" (BASTOS, 1984, p. 97). Os alunos estariam sentindo necessidade de uma gramática mais complexa para produzir o texto escrito, por um lado, e, por outro, não conseguiriam "[...] relacionar norma culta com texto oral" (BASTOS, 1984, p. 97).

Percebe-se, assim, que nos trabalhos produzidos no período considera-se a relação entre oralidade e escrita em sua associação com as possibilidades de transformaçóes que a escola poderia promover nas possibilidades de usos de linguagem dos sujeitos. A escola (ou a escolarização) teria a função discursiva de constituir referência para a tematização de diferenças sociais, econômicas e linguísticas, diferenças que se evidenciariam pela função catalisadora que a escola possuiria ao representar a coesão institucional diante da diversidade social. 
Nesse sentido, na pesquisa de Bastos (1985), as questóes relativas à variação linguística são tratadas de modo a percebê-las associadas a variações socioculturais e a fatores, apontados por Tarallo (1985), como classe econômica, etnia, sexo e idade. As considerações sobre variação se encaminham, então, para as possibilidades de alteração da variedade linguística do indivíduo, o que é apresentado com base em pesquisas de Labov (1974). Em seu trabalho, Bastos (1985) tem como objetivo conhecer de que modo acontece a apropriaçáo de conhecimentos linguísticos pelos alunos participantes da pesquisa, observando "[...] quais eventos gramaticais oferecem ao aprendiz da quinta série do primeiro e do terceiro ano do Segundo Grau, maior dificuldade na sua apreensáo, e de que forma o mesmo conhecimento, uma vez adquirido, é transposto para a linguagem escrita" (BASTOS, 1985, p. 8).

No que se refere ao tratamento dos dados, na investigaçáo de Bastos (1985) utilizam-se de conhecimentos produzidos pela tradição gramatical, justificando a autora tal opção tanto com base em discussóes realizadas em torno de ideias produzidas nos estudos linguísticos quanto com base nas propostas de ensino de Língua Portuguesa encontradas nos documentos oficiais. Assim, a relaçáo entre conhecimento gramatical e desempenho linguístico (escrito, nesse caso) se fundamentaria nas consideraçôes da Psicolinguística - encontradas em Slobin (1978) - sobre a necessidade de o falante conhecer "convençóes ou regras linguísticas particulares". Desse modo, ainda que se mencionem as propostas da Linguística quanto a ser necessário enfatizar os aspectos semânticos no ensino de "Português a quem já fala o idioma", e do caráter subsidiário que teria a gramática (de inspiração chomskiana) nesse processo, direciona-se argumentativamente o texto para a defesa da importância de se considerar o conhecimento gramatical "[...] como uma das múltiplas variáveis capazes de concorrer positiva ou negativamente para o alcance do alvo proposto" (BASTOS, 1985, p. 8) - qual seja, a melhora do desempenho linguístico.

Ainda que trabalhe argumentativamente em face da polêmica resultante da aproximação de perspectivas concorrentes sobre língua e ensino de língua, Bastos (1985) procura se afastar de tal polêmica em razão dos objetivos da investigaçáo, qual seja: "[...] verificar de que forma o aprendiz utiliza o conhecimento gramatical que possui, na elaboração de trabalhos de redaçáo" (BASTOS, 1985, p. 8).

A investigação levaria à conclusão, a partir de análises estatísticas, de que os alunos ampliam seus conhecimentos gramaticais ao longo do 
processo de escolarização, e que essa ampliação se refletiria em suas produçóes escritas, o que apontaria para a necessidade de não se julgar inadequado o conhecimento gramatical tradicional, mas os modos como esses conhecimentos são apresentados na escola (a sugestão feita, então, foi a de que se avaliassem os manuais de ensino e os usos que deles se fizessem em sala de aula). Ainda assim, se foi constatada evolução, questiona-se, ao final, que ela não se fez tal como esperado em função dos objetivos estabelecidos de proporcionar "[...] adequada e eficiente comunicação oral e escrita" e "[...] facultar o uso da língua para outros fins, além da interação social” (BASTOS, 1985, p. 67).

No trabalho de Bastos (1985), a delimitação entre discursos se faz com base na concorrência entre gramática tradicional e estudos linguísticos, uma vez que parte da relação entre modalidades com base em noçôes de língua e linguagem e nos processos de normatização que seriam evidentes no contexto escolar. Já no trabalho de Gallo (1989), o dispositivo para a constituiçáo da escrita escolar em objeto de análise também se constrói em torno da relação oralidade-escrita e da questão da normatização linguística; porém, neste caso, a base para as consideraçóes quanto à relação entre as modalidades não é gramatical, mas enunciativa, e a polêmica com que delimita seu espaço discursivo se constitui com base na concorrência entre o linguístico e o discursivo.

Sua investigação em nível de mestrado se originou, segundo Gallo (1989), de seu desejo de observar o que então compreendia como "[...] uma diferença entre a produção oral e a escrita" de seus alunos (GALLO, 1989, p. 2). A hipótese com que trabalhava era a de que os alunos se apropriavam mais daquilo que produziam oralmente, e que a diferença no modo como se relacionavam com a escrita se deveria ao fato de que oralidade e escrita constituiriam práticas diversas e fariam parte de um processo que se caracterizaria por ser discursivo (p. 3). Estabeleciam-se, assim, os princípios metodológicos de sua pesquisa, uma vez que a atenção deixava de se colocar no produto final, o texto, para considerar a produção linguística, "[...] no momento mesmo de sua constituição" (GALLO, 1989, p. 4). A Análise do Discurso responderia a esse princípio metodológico ao mobilizar questôes sobre o sujeito e o sentido (GALLO, 1989). O objetivo do trabalho seria o de mostrar que é possível ensinar o discurso escrito na escola, o que se faria segundo duas condiçóes: ensinar como se produz tal discurso e promover condiçóes para que esse texto seja produzido pelos alunos (GALLO, 1989).

Assim, após apresentar a tipologia proposta por Orlandi (1983) para o discurso (discurso lúdico, polêmico e pedagógico), Gallo (1989) discute se a 
diferença de modalidade (oral/escrita) pode de fato ser pensada como diferença discursiva, e questiona sobre que tipologia discursiva explicaria a diferença entre o texto oral e o texto escrito produtos do discurso pedagógico. A investigação, segundo Gallo (1989), se iniciaria com a tentativa de compreensáo dos modos de institucionalização da oralidade e da escrita.

Partindo da discussão sobre a dicotomia língua X fala em Saussure, a autora se encaminha para demonstrar que a língua não seria objeto da Linguística se tomada como produto, mas que o seria, tanto em sua modalidade oral quanto escrita, se consideradas como processo, uma vez que o próprio Saussure consideraria que a língua, como sistema, seria atravessada, por vezes, pela língua literária (SAUSSURE, 1977). A escrita estaria mais sujeita que a oralidade à normatização, devido à hegemonia que possui na sociedade burguesa e aos efeitos que se produzem nessa sociedade quanto à possibilidade de produção de um sentido único com base no escrito. A oralidade, por sua vez, poderia se instituir como forma marginal, produzindo sentidos ambíguos e inacabados, "[...] não por não ser produzida de acordo com a norma, mas exatamente por não passar pelo processo de legitimação" (SAUSSURE, 1977, p. 56).

Percebe-se, no trabalho de Gallo (1989), que a escola, nesse momento, ocupa a posição de referência para o tratamento das diferenças entre oralidade e escrita. A relação entre as condiçóes intra e extraescolares de produção do texto é não apenas tematizada de modo a possibilitar a abordagem teórica da questão, mas também de modo a possibilitar o movimento do pesquisador, que se encontra também no lugar de professor, no interior do próprio contexto escolar, em tentativas de promover a transformação das condiçôes de produção do texto e das possibilidades linguísticas dos alunos.

Esse movimento do pesquisador para o interior da escola é percebido também no trabalho de Sato (1989). O objetivo do trabalho da autora é o de analisar um projeto de ensino desenvolvido durante um semestre em um curso noturno de $2^{\circ}$ Grau de escola pública, no $2^{\circ}$ ano colegial (SATO, 1989). A prática pedagógica é o objeto de seu trabalho de análise, cujo objetivo seria o de encontrar marcas linguísticas nos textos dos alunos que evidenciassem reflexos do trabalho pedagógico realizado ao longo de um semestre (SATO, 1989, p. 12). Dadas as dificuldades que seriam advindas do "desconhecimento das especificidades dos códigos oral e escrito" (SATO, 1989, p. 13), realizou-se em sala de aula uma sequência de atividades com o objetivo de promover o desenvolvimento dos conhecimentos relativos a elementos próprios à escrita. 
Em seu trabalho, a relação entre normatização e diferenças entre modalidades é tratada considerando-se que os problemas na modalidade escrita, encontrados nos textos produzidos pelos alunos, seriam decorrentes da transposição, para o escrito, de elementos próprios à modalidade oral.

Segundo Sato (1989), as consideraçóes sobre linguagem teriam sido feitas de acordo com a perspectiva da forma e do uso, e não com base em análise de conteúdo. Nesse sentido, a relação oralidade-escrita, um dos pontos de vista privilegiados pela investigação, teria assumido destaque, colocando-se no centro das discussóes. Os trabalhos de análise se voltariam, então, para a procura de marcas de oralidade nos textos escritos dos alunos, consideradas as questóes sobre variação linguística, registro e normatização. Os problemas de escrita seriam decorrentes, por exemplo, da transposição para a escrita da "espontaneidade característica da conversação" (SATO, 1989, p. 73), ou pela "[...] oscilação entre registro formal e informal, que pode ser entendida como alternância entre oral e escrito" (SATO, 1989, p. 88).

A proposta da autora seria a de conhecer os recursos da oralidade como forma de rever as bases do ensino tradicional e seus resultados para a aprendizagem da escrita, uma vez que possibilitaria tratar de questôes relativas a dados socioculturais e situacionais, tal como apontados pela Análise da Conversação - o autor referido é Marcuschi (1986) -, além de diferenciar o trabalho com as modalidades, considerando os princípios de planejamento e editoração próprios à escrita, evidenciando-se também seu caráter de permanência.

Como observado acima, a referência à relação oralidade-escrita nos trabalhos desenvolvidos no momento histórico observado tem a função de organizar os processos de delimitação de espaços e a construção de objetos discursivos. A tematizaçáo das diferenças entre as modalidades, e as questóes sobre norma e variação que se colocam, possibilita o agenciamento de perspectivas teóricas específicas para seu tratamento, que se realiza com base em elementos da Sociolinguística, da tradição gramatical ou das teorias do discurso.

O tratamento da escrita escolar como material de análise permite, então, que, num sentido, o pesquisador se movimente entre referenciais teóricos determinados e deles se aproprie para o tratamento da questáo considerada; e, num outro sentido, que as diferenças entre modalidades sejam associadas a diferenças entre as condiçóes extra e intraescolares, ocupando posiçóes diversas, 
entre esses dois índices, segundo se movimente para considerar essas condições de um ou de outro ponto de vista.

Como será observado a seguir, esse movimento possibilita a apropriação de elementos teóricos para o tratamento da própria delimitação desses espaços e da caracterização de suas condições. O percurso, como já observado quando do tratamento da relação entre as modalidades oral e escrita, se direciona do exterior para o interior da escola.

\section{As condições (intra e extraescolares) de produção do texto}

As diferenças entre as condições intra e extraescolares na escola são tematizadas, nos trabalhos observados, de modo a que se agenciem referenciais teóricos que auxiliem no processo de compreensão dos problemas de escrita encontrados em textos escolares. As diferenças nas condiçóes de produção se relacionariam, nesse sentido, às características formais dos textos, que são analisadas com base em elementos da tradiçâoo gramatical, da linguística textual ou da análise do discurso.

Assim, uma característica apontada por Almeida (1980) para as produçóes escritas analisadas em seu trabalho estaria no comportamento dos sujeitos diante da escrita: problemas de ortografia, pontuação e concordância estariam presentes nos textos de sujeitos de ambas as classes sociais observadas em seu trabalho, mas em maior número nos textos produzidos por alunos da classe B (menos favorecida economicamente). Essa situação talvez se explicasse, principalmente no caso dos problemas de concordância, pelo fato de esses alunos registrarem na escrita estilo próximo ao que realizam em seu uso coloquial oral. Suas narrativas orais e escritas não apresentariam, assim, diferenças quanto ao estilo, prevalecendo, portanto, o coloquial. No mesmo sentido, o uso ou náo-uso de determinados recursos seria também condicionado por sua relação com aspectos próprios a determinada modalidade ou a determinado nível socioeconômico, devido a que, nas palavras da pesquisadora, "[...] muitos desses conectivos são itens característicos da produção escrita do adulto de nível sociocultural alto (conjunções como salvo se, contudo, conquanto), à qual nossos informantes não estão expostos" (ALMEIDA, 1980, p. 84).

O mesmo se afirma para a coesão lexical, quando se considera que ela “[...] terá mais possibilidade de ocorrer entre indivíduos que apresentem um vocabulário mais rico" (ALMEIDA, 1980, p. 91), e esse conhecimento teria 
influência do meio sociocultural a que pertence a pessoa. Os informantes de classe A, por serem mais favorecidos economicamente, enfrentariam com mais frequência situações que exigiriam uma fala mais elaborada, e, em função disso, "[...] mesmo num estilo coloquial, empregam o item lexical 'correto' ('jogavam' em vez de 'tacar'), empregam vocábulos mais eruditos (verbo haver, por exemplo), usam voz passiva” (ALMEIDA, 1980, p. 93).

Assim, a autora chega à conclusão de que não haveria, no que se refere ao uso de mecanismos de coesão, "[...] grandes diferenças, entre os grupos sociais analisados, quanto à variação entre linguagem oral e escrita", havendo "[...] diferenças significativas quanto às variáveis sociais (sexo e classe do informante)" (ALMEIDA, 1980, p. 141). As meninas de classe A, por exemplo, apresentariam índice mais alto quanto ao uso de recursos coesivos na modalidade escrita e índice quase táo alto na modalidade oral. Os dados confirmariam, então, a hipótese de que níveis culturais e econômicos mais baixos estariam relacionados com certa insegurança linguistica, que se refletiria em variação no uso dos mecanismos de coesão (ALMEIDA, 1980).

No trabalho de Almeida (1980), as diferenças sociais e econômicas são observadas em sua influência sobre as produções linguísticas do aluno, mas não se tematiza a função da escola para a manutenção ou alteração das possibilidades de uso da linguagem dos sujeitos (não seria esse o objetivo do trabalho). A escola seria o lugar em que essas diferenças se evidenciam, considerando-se o papel normatizador da instituição, que prevê o ensino do padrão da língua às diversas classes componentes da sociedade.

Já no trabalho de Bastos (1984), a função da escola para a modificação das possibilidades individuais de uso da língua é considerada e é referência para a discussão sobre as diferenças que se apresentam, em contexto escolar e não escolar, nas condiçóes de produção do texto oral e do texto escrito.

Os problemas de coesão e coerência são observados considerando-se as relaçóes entre as condiçôes intra e extraescolares não a partir de questôes explícitas sobre fatores socioeconômicos, mas a partir de características próprias aos modos de interlocução. No que se refere às diferenças entre as condiçôes intra e extraescolares, a pesquisa de Bastos (1984) se organiza, entâo, em torno de dois pontos: a preocupação com "um modelo de organização e funcionamento do texto narrativo", e "a inserção do texto numa situação de interlocução" (BASTOS, 1984, p. IX). Da relaçấo desses dois pontos, são observados os problemas de coesão e coerência na escola, decorrentes, nesse contexto, de o 
aluno não conseguir definir quem seja seu interlocutor e as condições em que produz seu texto (BASTOS, 1984).

A narrativa foi o tipo de texto escolhido para compor o corpus da pesquisa pelo fato de permitir representar as transformaçóes da realidade e informá-las ao interlocutor. Além disso, os alunos trariam para a escola a capacidade de produzir narrativas orais, conhecimento que seria ignorado por essa instituição, que privilegiaria a narrativa escrita. Mesmo o exercício da escrita seria também problemático em contexto escolar, pois os alunos não dominariam grande parte dos conhecimentos linguísticos à sua disposição, e, além disso, o aluno pouco se comprometeria com seu texto e não teria nunca um interlocutor verdadeiro.

Segundo Bastos (1984, p. 94), os problemas encontrados nos textos analisados "[...] relacionam-se diretamente com a necessidade de definição de uma situação de interlocução", dada a dependência da coerência em relação à definição de um interlocutor. Os problemas de coesão encontrados nos textos analisados seriam entấo decorrentes, em parte, da não-definiçấo das condiçôes de produção do texto na escola.

Assim, a autora, em sua pesquisa, caracteriza as diferenças existentes entre as condiçóes de produçáo de texto na escola e fora dela, e o faz com a análise de textos escritos produzidos em situação que se aproximaria das condiçóes de produção de textos orais que o aluno já dominasse e trouxesse para o interior da sala de aula.

Subjacente à estratégia utilizada na pesquisa para a diferenciação entre condiçóes intra e extraescolares de produção do texto, parece se encontrar a distinção entre competência linguística, associada à capacidade do sujeito de produzir textos orais, e desempenho linguístico, associado à necessidade de desenvolvimento da capacidade de produção de textos escritos. Competência e desempenho, por sua vez, estariam em situação de dependência para com a apropriação de recursos gramaticais, de modo que o sujeito pudesse desenvolver suas possibilidades de uso da linguagem com o objetivo de aproximar-se do padrão da língua. Como já mencionado, para a autora, essa aproximação se realizaria com base no tratamento dos aspectos textuais relacionados à diferença entre oralidade e escrita, dada a "[...] necessidade de uma gramática mais complexa para produzir o texto escrito" (BASTOS, 1984, p. 97), de que sentiria falta o aluno, que também não conseguiria "[...] relacionar norma culta com texto oral" (BASTOS, 1984, p. 97). 
Movimento semelhante se percebe no trabalho de Bastos (1985), que parte de questionamentos próximos aos de Bastos (1984) quanto às relaçôes entre o conhecimento linguístico com que o sujeito chega à escola e aqueles que nela ele desenvolveria; e, também, quanto às relaçôes entre conhecimento linguístico e seu desenvolvimento em situação de ensino. No trabalho desenvolvido por Bastos (1985), a delimitação discursiva para a constituição do objeto de análise se fundamenta na distinção entre as concepções de linguagem dos estudos linguísticos e as concepçôes de linguagem fundamentadas nos saberes gramaticais tradicionais. Assim, a apropriação de saberes gramaticais mais complexos, que promoveriam o desenvolvimento da competência escrita dos alunos, se realizaria com base na aprendizagem dos saberes linguísticos da gramática tradicional.

A autora discute, entâo, questôes relativas à aprendizagem da língua, considerando que sua aquisição se faz de forma gradual, de habilidades mais simples às mais complexas, até um ponto em que o aluno necessita de ajuda para enriquecer seu desempenho. Nesse ponto, a escola teria importante papel para a aprendizagem da leitura e da escrita, de modo que se tornasse possível para a criança "[...] usar a língua para outros fins, além da interaçáo social" (BASTOS, 1985, p. 5).

A apropriação do padrão da língua parece ser o fator necessário para que o indivíduo possa produzir textos que não apenas aqueles utilizados na "interação social", isto é, aqueles produzidos com base em competências desenvolvidas pelo indivíduo em sua comunidade primeira. A escola seria o lugar em que se ampliariam as possibilidades linguísticas e culturais dos sujeitos, sendo, assim, o principal agente social a garantir o desenvolvimento linguístico dos indivíduos.

O texto se inicia apontando a importância da língua para a "[...] manifestação-recepção de pensamentos, promovendo o intercâmbio indivíduosociedade" (BASTOS, 1985, p. 2), importância que seria inferida das ideias linguísticas elaboradas por autores como Saussure (1977), Martinet (1970), Benveniste (1976) e Malmberg (1976). Citados quando do tratamento de questôes relativas à comunicação ou à relação linguagem-cultura, recortam-se, de cada obra referida, passagens em que se destacam as funçóes representacional e organizativa da linguagem. Essas funçôes possibilitariam a relação constitutiva entre o individual (que se apropriaria do legado cultural, construído e armazenado pelo uso da língua) e o social (que resultaria da contribuição de 
cada indivíduo para os conhecimentos linguísticos e para a produção cultural do grupo) (BASTOS, 1985).

No trabalho de Bastos (1985), parece haver a aposta nas possibilidades que o saber escolar ofereceria para a apropriação de conhecimentos linguísticos que sustentassem a produçâo de textos mais complexos que aqueles da cultura oral em que se desenvolveram os indivíduos. A ideia de um aumento gradual de complexidade nos usos de linguagem, em que se fundamenta a autora ao tecer suas consideraçóes sobre ensino e aprendizagem de língua, e a não-tematização das diferenças entre os aspectos intra e extraescolares no que se refere às condiçōes de produção de textos sugerem a ideia de um continuum entre escola e demais instituiçōes sociais.

Gallo (1989), por sua vez, observa não um princípio de continuidade entre outras instituições e a escola, mas percebe um fator de ruptura entre as condiçóes extraescolares e as intraescolares de produção de textos. Após discutir questóes relativas a noçóes como as de língua portuguesa, língua brasileira, autor nacional e a de função-autor, com base em Foucault $(1971,1983)$ e Orlandi e Guimarães (1988), Gallo (1989) trata do papel da escola em sua função institucional e do lugar do aluno escrevente nesse espaço. Segundo a autora, a escola se constitui como o lugar de conservação dos discursos oral e escrito, o que faz apresentando aos alunos o discurso escrito como aquele que é modelar, cuja forma é normativa. Tal prática legitimaria o discurso escrito, em que se representaria um sentido único, desambiguizado.

Assim, com base na relação oral/escrita, e nas questốes referentes a variação e normatização linguística colocadas em função desses elementos, são considerados os fatores intra e extraescolares que concorreriam para a constituição das condiçóes de produção da escrita escolar. Nesse sentido, a autora chama a atenção para o fato de que a escola náo ensina o discurso que legitima, pois o lugar próprio de existência do discurso escrito seriam as instituiçóes responsáveis pela produção desse discurso (citam-se, como exemplos dessas instituições, o jornal, o livro, a publicidade, a revista, a TV, o rádio). A escola, por sua vez, se caracterizaria não como produtora, mas como mantenedora do discurso escrito, que seria apresentado, analisado, estudado, mas nunca ensinado aos alunos, cuja produção permaneceria, após a escolarização, inscrita no discurso oral. Mesmo que conseguissem apreender as normas e ajustar a elas os textos que produzem, ainda assim os alunos permaneceriam inscritos no discurso oral, pois suas produções não seriam legítimas como seriam as de 
um jornalista, por exemplo, e não produziriam um sentido único. Por não ser instância produtora do discurso escrito, a escola não propiciaria as condições necessárias para que os sujeitos se constituíssem autores.

A proposta da pesquisadora, que fundamenta inclusive a metodologia de pesquisa em sua investigação, é a de promover transformações nas condiçóes escolares de modo a possibilitar a produção do texto escrito, superando a ruptura que se estabeleceria, na escola, entre o discurso escrito e o discurso oral. Percebe-se, assim, que, diferentemente dos modos como considerados no trabalho de Bastos (1985), neste momento das discussóes sobre ensino da escrita na escola, a instituição escolar é considerada segundo ponto de vista que procura observá-la em seu interior. O pesquisador é também o agente que atua em busca de transformaçóes no contexto de ensino.

Essa mudança de posicionamento do pesquisador é percebida também no trabalho de Sato (1989). A alteração das condições de ensino é igualmente o fator que fundamenta a discussão da autora sobre as causas dos problemas de escrita, que estariam não no exterior da escola, mas em seus modos de organização. Assim, ainda que tenha realizado em seu trabalho de pesquisa a caracterização sociocultural dos alunos, os resultados obtidos foram considerados periféricos para a investigação, pois, segundo a autora, "[...] os textos analisados parecem não refletir influência ponderável dos fatores presentes nas respostas aos questionários" (SATO, 1989, p. 16). Os problemas de escrita são associados ao autoritarismo vigente na escola, o que resultaria na infantilidade encontrada em muitas das produçōes escritas analisadas.

Além dos problemas decorrentes do autoritarismo, que seria próprio às relaçōes escolares de um modo mais geral, apontam-se, com base em trabalhos de Geraldi (1984), Ilari (1985) e Lemos (1977), elementos característicos da disciplina de Língua Portuguesa que estariam na base dos problemas detectados nas práticas de ensino. O caráter de simulação apontado por Geraldi (1984) para a escrita, a leitura e a análise linguística, tais como realizadas em contexto escolar, é destacado por Sato (1989), que indica também a necessidade de consideração de interlocutor para o texto a ser produzido, o que a escola não faria adequadamente ao concentrar na figura do professor o destinatário da produção escrita, ou ao eliminar qualquer projeção de leitor específico a fim de garantir liberdade à imaginação e à criatividade do aluno.

Outro elemento responsável pelos problemas de ensino e aprendizagem da escrita se referiria à imagem de língua culta da escola, língua que não se 
destinaria ao uso, mas ao aprendizado de regras: "o abismo entre as aulas de redação e as de gramática" impossibilitaria que se estabelecesse relação "entre expressão correta e conhecimento gramatical" (SATO, 1989, p. 18). A proposta da pesquisadora seria a de possibilitar a existência de um ambiente escolar que oferecesse condições para que a produção de linguagem fosse exercitada "no maior número possível de funçôes" (SATO, 1989, p. 20).

Um aspecto também tematizado no trabalho de Sato (1989) quanto às causas dos problemas de escrita na escola se refere ao princípio do dialogismo e aos modos como se construiriam os papéis do locutor e do interlocutor em contexto escolar. Referindo Bakhtin $(1963 ; 1974)$ e as propostas do autor para se compreender o ideológico e o dialogismo, a autora menciona a dificuldade para se representar o interlocutor na produçáo do texto escrito, e as consequências dessa dificuldade para a constituição da representação do próprio locutor, uma vez que o interlocutor possuiria "função reguladora sobre o produtor" (SATO, 1989, p. 60). A função reguladora teria consequências também para os próprios processos coesivos (faz-se, então, referência ao trabalho de Pécora (1983)).

Assim, os problemas de escrita persistiriam na escola, mesmo depois do próprio desenvolvimento das atividades realizadas durante a investigaçáo, devido "[...] à falta de domínio da modalidade escrita e à ausência de uma relação de interlocução claramente explicitada na escola ou à presença de uma relação fixa de interlocução professor/escola-aluno" (SATO, 1989, p. 113), de que se originariam os problemas de coerência nos textos escritos analisados.

Os problemas de redação se refeririam, além de à situação de produção escrita na escola, também ao problema da formação do professor e ao fato de este não se constituir como interlocutor real, pois materializaria a instituição escolar, que determinaria, para o aluno, uma determinada representação de lingua culta.

Num certo sentido, as consideraçóes de Sato (1989) quanto aos modos de interlocução existentes na escola retomam as discussóes de Bastos (1984) sobre o mesmo tema, mas, neste momento, com base nas açóes realizadas pela pesquisadora sobre as condiçóes de produção de texto em contexto escolar, com o objetivo de modificá-las.

A observaçấo dos modos de tratamento das condiçôes de produção do texto na escola sugere um deslocamento das posiçôes ocupadas pelos pesquisadores em seus trabalhos investigativos. Nesse deslocamento, que 
tem como referência os índices estabelecidos pela oposição entre o extra e o intraescolar, o movimento de aproximação à escola se realiza em paralelo com a aproximação entre pesquisador e professor, que atinge seu ápice no momento em que a pesquisa se volta para a observação de alteraçôes promovidas nas condiçôes de ensino pela própria atuação do pesquisador-professor. Esse movimento parece possibilitar a apropriação de saberes teóricos sobre língua e sobre texto, num processo em que a escrita escolar se constitui objeto de discurso.

\section{O agenciamento de recursos teóricos e a constituição da escrita escolar em objeto de discurso}

O movimento realizado pelo pesquisador em sua aproximação das condiçóes escolares de produção do texto tem como referência os índices de tempo e espaço, a oposição entre oralidade e escrita, e a diferenciação entre contextos extra e intraescolar. No movimento entre um e outro dos polos que compóem os pares em questáo, opera-se o processo de apropriação de saberes elaborados pelos estudos linguísticos sobre língua e texto, o que possibilita constituir a escrita escolar em objeto de discurso.

Para realizar esse trabalho, Almeida (1980) fundamenta teoricamente sua investigação em torno do conceito de coesão, tal como elaborado pela Linguística Textual, principalmente por Halliday e Hasan (1975), mas amplia a discussão ao relacionar esse conceito a noçóes vindas da Sociolinguística e a consideraçóes quanto a aspectos lexicais.

Percebe-se, na pesquisa de Almeida (1980), a associação das modalidades oral e escrita a registros mais ou menos formais, o que, em situação escolar, se organizaria segundo um percurso caracterizado como não apenas formativo, mas também normativo. Esse percurso, que se direciona do mais informal, localizado no espaço extraescolar, ao mais formal, localizado no interior da escola, possibilita associar conceitos apropriados aos estudos linguísticos, acima referidos, a elementos próprios à tradição gramatical, principalmente com base nos trabalhos de Cunha (1975), Rocha Lima (1973) e Bueno (1975). Assim, os mecanismos de coesão, tais como elaborados pela Linguística Textual, são observados, nos textos que compóem o corpus da pesquisa, em sua relação com fatores próprios ao processo de normatização linguística, o que aproxima discursos diferentes, muitas vezes percebidos em situaçáo de oposição (os estudos linguísticos e a tradição gramatical), para o tratamento do objeto de análise. 
Princípio semelhante seria percebido no trabalho de Bastos (1984), que compartilha com o de Almeida (1980) a perspectiva de que os problemas textuais seriam decorrentes das diferenças nas condiçóes de produção do texto oral e do texto escrito, e que essas diferenças se refletiriam nos processos de organização textual. O trabalho de Bastos (1984) também faz menção às necessidades de desenvolvimento dos recursos gramaticais dos sujeitos de modo a ampliarem suas possibilidades de produção textual. O que se altera, entre uma pesquisa e outra, é o lugar que se projeta para o aluno, sujeito produtor dos textos analisados: se, para Almeida (1980), o texto é resultante dos recursos linguísticos que possui o sujeito para expressar seu pensamento (o que confere primazia ao linguístico em relação ao textual), para Bastos (1984), o texto é produto dos modos de interlocução (o que confere primazia ao texto em relaçáo ao linguístico). Assim, segundo Bastos (1984), a coerência dos textos narrativos se estabeleceria em dois níveis: do "narrar como ato de fala", que seria definido culturalmente; e "da inserção do texto numa situação de comunicação" (BASTOS, 1984, p. 22). Para a autora, os alunos conheceriam o esquema narrativo próprio de sua cultura e saberiam narrar de acordo com ele; os problemas textuais seriam decorrentes do modo de inserção do texto na situação de interlocução, situação que apresentaria questóes específicas em contexto escolar.

A autora aponta para o fato de que a coerência, tal como prevista nos modelos referenciados - de Labov e Waletzky (1967), Larivaille (1974), Weinrich (1973, 1979), Benveniste (1976), e Simonin-Grumbach (1975) -, estaria presente nos textos escolares analisados, não se encontrando, porém, modelos fixos de coesão. Aponta, também, para a ocorrência, nos dados, da transposiçáo para a escrita de recursos que seriam eficazes para o estabelecimento de coerência e coesão em textos orais, transposição que seria a causa da aparente falta de coesáo e de coerência nos textos escritos analisados.

No trabalho de Bastos (1984), a relação entre conhecimentos linguísticos e conhecimentos textuais se constrói de modo que a competência linguística do sujeito não seja questionada, e que apenas o desempenho seja considerado em sua relação com as condiçôes de produção. A escola referencia o limite espacial e temporal entre a competência e o desempenho que o aluno desenvolve em seu grupo social primeiro, em que tem primazia a modalidade oral; e a competência e o desempenho que o aluno desenvolve em contexto escolar, em que tem primazia a modalidade escrita. Com o pressuposto da competência linguística do sujeito, as possibilidades de pensamento e de comunicação estão 
garantidas a priori, o que se evidencia na anterioridade conferida à coerência em relaçáo à coesão. $\mathrm{O}$ processo escolar teria, então, o objetivo de ampliar os recursos linguísticos dos sujeitos, de modo que pudessem realizar formalmente os processos ilocucionários de que se apropriariam em relações de interlocução distintas das que já possuiriam de suas experiências linguísticas anteriores à escolarização.

Observam-se, assim, dois deslocamentos importantes no trabalho de Bastos (1984): o primeiro se refere ao movimento, operado com a base teórica da pesquisa, da língua em direção ao texto. Esse movimento permite observar dissociadamente linguagem e pensamento, e perceber a sistematização escolar dos conhecimentos gramaticais não em relação à competência, mas em relação ao desempenho. Tal deslocamento é importante, pois possibilita ao pesquisador constituir para si uma posição externa, não apenas em relação à tradição gramatical, mas também em relação aos estudos linguísticos de base formal.

O segundo deslocamento se refere à posição assumida pelo pesquisador em relação ao próprio contexto escolar, que pode ser, então, percebido em suas especificidades espaciais e temporais não apenas em função de seu papel de legitimação de uma dada norma linguística, que referenciaria o julgamento das demais, mas como um contexto institucional, que se soma aos demais não sob o viés da continuidade, mas da diferença.

Esse movimento em direçáo ao interior da escola, que se encontra no trabalho de Bastos (1984), evidencia-se também no trabalho de Bastos (1985), quando considera os fatores condicionantes da produção textual. Nesse caso, os fatores considerados se referem aos modos como são ensinados e aprendidos os conhecimentos gramaticais em contexto escolar. Porém, o texto produzido em contexto de ensino, ainda que condicionado por esses fatores, parece constituir uma unidade com estruturação própria e autonomia, podendo ser encontradas em sua materialidade as marcas do processo de sua elaboração e das condiçóes de sua produção. Assim, a escola é apreendida em suas especificidades, marcando-se os limites entre o que são conhecimentos extraescolares e o que são conhecimentos intraescolares.

A diferença que se encontra entre o trabalho de Bastos (1985) e os dois outros acima referidos diz respeito aos modos como a questão da variação linguística é considerada em sua relação com elementos da relação oralidadeescrita: a relação entre a língua do aluno e a língua da escola se faz a partir dos princípios de gramaticalidade, que concentram o que se considera a 
respeito dos conhecimentos linguísticos que o aluno possui, e aqueles que a escola sistematiza. Nesse sentido, a discussão realizada pela autora se apoia em estudos linguísticos, quando fundamenta teoricamente sua pesquisa, e em conhecimentos gramaticais tradicionais, quando considera o trabalho em sala de aula.

As relaçóes entre os aspectos intra e extraescolares se fazem, assim, no trabalho de Bastos (1985), com base em duas diferentes concepçóes de gramática, que, ocupando posiçóes distintas na estrutura da investigação, possibilitam relacionar o tratamento escolar da escrita, de caráter normativo, às discussóes de caráter descritivo-explicativo em torno da variação linguística, característica da modalidade oral trazida à escola pelo aluno.

A alternância entre descrição e prescrição possibilita, assim, a abordagem do material de análise em sua relação com fatores intra e extraescolares, e, associadamente a esses fatores, em sua relação com as questôes relativas à oralidade e à escrita: nesse movimento, produzem-se os dados a partir do material escrito disponível, isto é, constitui-se a escrita escolar em objeto de análise.

O processo de delimitação recíproca entre estudos linguísticos e tradição gramatical se resolve no trabalho de Bastos (1985) com o movimento ambivalente assumido pelo pesquisador em relação aos aspectos extra e intraescolares, em que se define a descontinuidade entre escola e demais instituiçóes sociais. O sujeito da investigação pode, então, ocupar a função de pesquisador, posicionando-se externamente em relação ao delimitado como contexto escolar, e de professor, ao posicionar-se internamente ao limite construído para referenciar as condições escolares de produção do texto.

Esse movimento ambivalente se encontra mais bem evidenciado no trabalho de Gallo (1989), que se desloca no sentido de alterar as condiçóes de produção de textos internas à escola, de modo a diferenciá-las das produzidas em contexto extraescolar, e, nesse processo, produzir em situaçáo de ensino a possibilidade da produçáo escrita. No caso da pesquisa desta autora, a perspectiva teórica utilizada para a produção e análise dos dados se fundamenta na Análise de Discurso de linha francesa. Relaciona-se o tratamento das produçóes de linguagem à teoria materialista da linguagem, fundada na história e na ideologia, sem abrir mão da questão da subjetividade e da descontinuidade (GALLO, 1989). O texto seria visto, então, como um produto a-histórico, mas que guardaria em si marcas que remontariam à materialidade histórica que está na origem de sua produção (GALLO, 1989). 
A hipótese da autora é a de que a possibilidade de os alunos inscreverem seus textos no discurso escrito se faria pela assunção da autoria, isto é, não apenas pela elaboração da funçấo-autor, mas pela explicitaçâo, para o sujeito, dessa elaboração. Seria necessário, para se sentir autor, que o sujeito não apenas produzisse seu texto, mas também soubesse como se realiza essa produção (GALLO, 1989), percebendo sua função de autor no momento em que conferiria unidade ao texto no trabalho com a ambiguidade permanente dos sentidos (GALLO, 1989). A norma não mais seria apresentada ao aluno como um dado necessário ao que o texto produzido teria de se adaptar, mas passaria a ser percebida como "[...] um dos efeitos de sentido produzido pelo discurso escrito - o efeito que faz parecer 'dado', o que é construção" (GALLO, 1989, p. 126). A escrita escolar, nesse caso, se constitui em objeto de pesquisa com base no princípio de sua negatividade em relaçáo ao que seja a escrita considerada legítima, produzida apenas em contexto não escolar. $\mathrm{O}$ trabalho da pesquisadora atuou sobre o trabalho da professora no sentido de promover positividades, em sala de aula, que produzissem condiçóes legítimas (como as não escolares) de produção do texto.

A norma, nesse momento, não é mais um dado diferenciador das modalidades oral e escrita em sua relaçâo com o contexto escolar, mas é percebida como um elemento do processo social de legitimação da língua, processo em que a escola se insere e possui funçóes de manutenção ou transformação da realidade linguística. Nesse sentido, se Gallo (1989) procura produzir em sala de aula condiçóes que possibilitem perceber o caráter de construto histórico da norma, Sato (1989) a considera em sua investigaçáo como um dado político a ser considerado como elemento do processo pedagógico.

Assim, no trabalho de Sato (1989), notam-se, nos princípios norteadores de trabalho em sala de aula, as influências das propostas oficiais de ensino de Língua Portuguesa fundamentadas em ideias linguísticas. Dentre esses princípios, destaca-se o apontamento quanto à necessidade de "relativização da norma culta" e de se mostrar aos alunos a diversidade de registros em funçáo do "contexto situacional" e das "condiçôes de produção".

A análise do corpus se direcionou para a relaçáo oralidade-escrita e para o texto produzido em contexto de sala de aula. A fundamentação teórica se fez com referência a elementos de linguística textual, com base em Halliday e Hasan (1973), e em discussóes que propusessem novos modos de perceber os conceitos de coesão e coerência, como a encontrada em Bastos (1984), além da 
consideração das diferenças entre o oral e o escrito - Marcuschi (1986); Kato (1986) -, e das características próprias aos gêneros desenvolvidos em sala de aula, considerando-se, então, questôes de argumentação - Koch (1987); Orlandi (1983) - e os elementos do narrativo - Labov e Waletsky (1967).

Percebe-se, no trabalho de Sato (1989), que o texto parece ser considerado autonomamente, como objeto de análise, não mais se caracterizando apenas como produto das condiçóes de produção, mas parte delas. Nos dizeres da autora, "[...] uma das pretensóes [do] estudo é a de abordar analiticamente textos de alunos enquanto uma totalidade discursiva, sem abrir mão de unidades linguísticas menores evidentemente" (SATO, 1989, p. 43).

A posição ocupada pela pesquisadora, nesse momento, se localiza no interior da escola, percebida como elemento constitutivo do social, e, portanto, situada política e historicamente. $\mathrm{O}$ texto escrito produzido em contexto escolar guardaria em si as marcas dessa historicidade, que trariam em sua memória também os traços próprios à instituição em que se produziram.

O movimento operado pela pesquisadora parece se fazer no sentido de colocar-se em situação de equivalência em relação à posição atribuída à professora. A primeira não mais responderia às questôes apresentadas pelas perspectivas teóricas que fundamentassem as pesquisas, de modo a compreender, a partir de uma exterioridade, o que aconteceria no contexto observado: nesse momento, parece se constituir um diálogo próximo com as posiçóes que sustentariam a própria prática de sala de aula, ocupando a professora o lugar de sujeito principal para as questôes de pesquisa. Em funçấo da ambivalência de sua posição, o sujeito se movimenta entre os lugares de professor e de pesquisador e, nesse movimento, se apropria dos subsídios teóricos necessários para que a escrita escolar se constitua em objeto de pesquisa.

\section{Considerações finais}

Nota-se, nos trabalhos observados, que os fatores extratextuais são considerados para o tratamento dos dados e sua análise. Porém, diferentemente das pesquisas sobre escrita escolar desenvolvidas nos anos finais da década de 1970 (PIETRI, 2012), os fatores externos não são percebidos como causas dos problemas de redaçáo, mas como condicionantes da produção do texto, podendo ser considerados tais condicionantes como elementos responsáveis pela organização textual. $\mathrm{O}$ texto é assim observado em sua unidade, com 
estruturação própria, ainda que essa estruturação tenha sido condicionada por fatores extralinguísticos.

A relação oralidade-escrita, ao ser associada a questóes de sociolinguística, possibilita que o trabalho de análise textual se faça movimentando-se das consideraçóes sobre o linguístico para as consideraçôes sobre o extralinguístico (e vice-versa); das consideraçóes sobre o texto para as consideraçóes sobre o contexto (e vice-versa).

A tematização das relaçôes oralidade-escrita fundamenta, nesse processo, a consideração de aspectos extraescolares, dado que a oralidade é associada aos saberes que o aluno traz à escola, e de aspectos escolares, dado que a escrita compóe o saber cuja transmissão estaria sob responsabilidade do ensino formal. Um e outro aspecto se constituem em polos para os quais se direcionam as discussóes realizadas nas pesquisas.

As posiçôes em que se encontram os aspectos escolares e extraescolares podem ser definidas, então, pela posição de referência que ocupa o objeto de pesquisa, de modo que as características dos textos escritos produzidos na escola se devam, em parte, ao fato de os alunos não terem conhecimentos sobre a modalidade escrita, e, de outro, de as condiçôes de produção do texto na escola não serem autênticas.

As consideraçóes em torno das condiçóes intra e extraescolares de produção do texto escrito, em sua associação com as questóes referentes à relaçáo oralidade-escrita, e, a partir desta, as discussóes em torno da variaçáo e da normatizaçáo linguística constituem, para as pesquisas observadas, um dispositivo que possibilita o movimento dos sentidos em alternância de um a outro polo: nesse movimento reversível entre condiçôes internas e externas, os fatores de textualidade se posicionam como índices discursivos para o sujeito em seu movimento, constituindo a escrita escolar em objeto de análise no momento mesmo em que é tomada como referente para a produção e apropriaçáo de conhecimentos linguísticos.

\section{Notas}

1 De fato, as mudanças curriculares que se apontam para a disciplina são compreendidas de modos diferentes nas instâncias pedagógicas e nas instâncias oficiais: a organização curricular prevista pela Lei no $5.692 / 71$ (BRASIL, 1971a) e pela Resolução CFE no 8/71 (BRASIL, 1971b) não 
reconfiguram a disciplina de Língua Portuguesa em sua ordenação interna (o que pode se verificar, por exemplo, no modo como constituídos os Guias Curriculares do Estado de São Paulo (São Paulo, 1975) ou os Subsídios aos Guias Curriculares (São Paulo, 1977), mas em sua localização no interior do currículo da escolarização básica, que, nesse período, se alterava para responder à ampliação do alcance do ensino público obrigatório - não mais apenas até a então denominada $4^{a}$ série do primário, mas até a $8^{a}$ série do ginásio (PIETRI, 2010).

2 Neste artigo, apresentam-se resultados de pesquisa financiada pelo $\mathrm{CNPq}$ (Processo n. 400540/2008-8).

\section{REFERÊNCIAS}

ADAM, Jean-Michel. A Linguística Textual: introdução à análise textual dos discursos. São Paulo: Cortez, 2008.

ALMEIDA, Maria Antonieta C. Coesão textual da linguagem dos préadolescentes. 1980. Dissertação (Mestrado em Educação) - Universidade Estadual de Campinas, Campinas, SP, 1980.

BAKHTIN, Mikhail. La poétique de Dostoievski. Paris: Seuil, 1963.

BAKHTIN, Mikhail. Marxism and the philosophy of language. New YorkLondon: Seminar Press, 1974.

BASTOS, Daisi Rocha. Análise do desempenho de adolescentes em teste gramatical e de sua transferência para a linguagem escrita.1985. $115 \mathrm{f}$. Dissertação (Mestrado em Linguística) - Universidade de São Paulo, São Paulo, 1985.

BASTOS, Lúcia K. X. Coesâo e coerência em narrativas escolares escritas. 1984. Dissertação (Mestrado em Linguística) - Universidade Estadual de Campinas, Campinas, SP, 1984.

BENVENISTE, Émile. Problemas de Linguística geral. São Paulo: Ed. da Universidade de São Paulo, 1976.

BRASIL. Lei no 5.692, de 11 de agosto de 1971. Fixa Diretrizes e Bases para o ensino de $1^{\circ}$ e $2^{\circ}$ graus, e dá outras providências. Diário Oficial da União, Brasília, DF, 12 ago. 1971a. 
BRASIL. Resolução no 8 , de 1 de dezembro de 1971. Fixa o núcleo comum para o currículos do $1^{\circ}$ e $2^{\circ}$ graus, definindo os objetivos e a amplitude.

Documento $n^{o}$ 133, Rio de Janeiro, dez.1971b.

BUENO, Francisco da Silveira. Gramática da língua portuguesa. São Paulo: Saraiva \& Cia, 1975.

CUNHA, Celso F. Gramática da língua portuguesa. 2. ed. Rio de Janeiro: Fename, 1975.

FOUCAULT, Michel. L'ordre du discours. Paris: Gallimard, 1971.

FOUCAULT, Michel. Qu'est-ce que un auteur? Littoral, Paris, n. 9, p. 3-32, 1983.

GALLO, Solange L. O ensino da língua escrita X o ensino do discurso escrito. 1989. Dissertação (Mestrado em Linguística) - Universidade Estadual de Campinas, Campinas, SP, 1989.

GERALDI, João Wanderley. Concepçôes de linguagem e ensino. In: GERALDI, João Wanderley (Org.). O texto na sala de aula: leitura \& produção. 2. ed. Cascavel, PR: Assoeste, 1985.

HALLIDAY, Michael A.K.; HASAN, Ruqaiya. Cohesion in spoken and written english. London: Longman's English Language Series, 1973.

HALLIDAY, Michael A.K.; HASAN, Ruqaiya. Cohesion in English. London: Longman, 1975.

ILARI, Rodolfo. Uma nota sobre redaçáo escolar. In: ILARI, Rodolfo. $A$ Linguistica e o ensino de Lingua Portuguesa. São Paulo: Martins Fontes, 1985.

KATO, Mary Aizawa. No mundo da escrita: uma perspectiva psicolinguística. 2. ed. São Paulo: Ática, 1986.

KOCH, Ingedore G. V. Argumentação e linguagem. 2. ed. São Paulo: Cortez, 1987.

LABOV, Willian. Estágios na aquisição do inglês standard. In: FONSECA, M.S.V.; NEVES, M. F. Sociolinguística. Rio de Janeiro: Eldorado, p. 49-85, 1974.

LABOV, Willian; WALETZKY, Joshua. Narrative analysis: oral versions of personal experience. In: HELM, J. Essays on the verbal and visual arts. Washington: University of Washington Press, p. 12-44, 1967. 
LARIVAILLE, Paul. L'analyse (morpho)logique du récit. Poétique, Paris, n. 19, p. 369-388, 1974.

LEMOS, Cláudia .T. G. Redaçóes no vestibular: algumas estratégias. In: Cadernos de Pesquisa, n. 23, p. 61-71, 1977.

LIMA, C. H. Rocha. Gramática normativa da Lingua Portuguesa. 16. ed. Rio de Janeiro: J. Olympio, 1973.

MAINGUENEAU, Dominique (Org.). Les analyses du discours en France. Langages. Paris: Larousse, 1995.

MAINGUENEAU, Dominique. Gênese dos discursos. Tradução Sírio Possenti. Curitiba: Criar Edições, 2005.

MALMBERG, Betil. A lingua e o homem. São Paulo: Duas Cidades, 1976.

MARCUSCHI, Luís Antonio. Análise da conversação. São Paulo: Ática, 1986.

MARTINET, André. Elementos de Linguistica geral. 2. ed. Lisboa: Sá da Costa, 1970.

ORLANDI, Eni Pucinelli. A linguagem e seu funcionamento. São Paulo: Brasiliense, 1983.

ORLANDI, Eni Puccinelli; GUIMARÁES, Eduardo. Unidade e dispersão: uma questão do texto e do sujeito. In: ORLANDI, Eni Puccinelli. Discurso \& leitura. São Paulo: Cortez; Campinas, SP: Ed. da Unicamp, 1988. p. 5373.

PÉCORA, Alcir. Problemas de redação. São Paulo: Martins Fontes, 1983.

PIETRI, Emerson de. A constituição da escrita escolar em objeto de análise dos estudos lingüísticos. Trabalhos em Lingüistica Aplicada, v. 46, p. 283297, 2007.

PIETRI, Emerson de. Sobre a constituição da disciplina curricular de língua portuguesa. Revista Brasileira de Educação, n. 43, v. 15, p. 70-83, 2010.

PIETRI, Emerson de. A constituição da escrita escolar em objeto de pesquisas acadêmicas. Cadernos de História da Educação, v. 11, n. 1, jan./ jun., p. 107-130, 2012. 
SÃO PAULO. Secretaria da Educação. Guias Curriculares para o ensino de $1^{\circ}$ grau. São Paulo: Cerhupe, 1975.

SÃO PAULO. Subsidios para a implementação do guia curricular de Lingua Portuguesa para o 1ํ Grau. São Paulo: CENP, 1977.

SATO, Nanami. O aluno e a produção do texto escrito: travessias. Uma análise de redaçóes de alunos do $2^{\circ}$ grau. 1989. Dissertaçáo (Mestrado em Educaçâo) - Universidade de São Paulo, 1989.

SAUSSURE, Ferdinand de. Curso de Linguistica geral. 8. ed. São Paulo: Cultrix, 1977.

SIMONIN-GRUMBACH, Jenny. Pour une typologie du discours. In: KRISTEVA, J.; MILNER, J.-C.; RUWET, N. Langue, discours, société. Paris: Éditions du Seuil, p. 85-121, 1975.

SLOBIN, Dan I. Psicolinguistica. São Paulo: Cultrix, 1978.

SOARES, Magda. Português na escola: história de uma disciplina curricular. In: BAGNO, M. (Org.). Linguística da norma. São Paulo: Edições Loyola, p. 155-177, 2002.

TARALLO, Fernando. A pesquisa sociolinguística. São Paulo: Ática, 1985.

VENTURI, Ioná V. G. \& GATTI JR., Décio. A construção histórica da disciplina escolar língua portuguesa. Cadernos de História da Educação, n. 3, p. 65-76, jan./dez. 2004.

WEINRICH, Harald. Les temps et les personnes. Poétique, Paris, n. 39, p. 338-352, 1979.

WEINRICH, Harald. Les temps. Paris: Éditions du Seuil, 1973. 
Orality, writing and the conditions of production of texts in the school: the constitution of school writing as an object of academic research

\begin{abstract}
This study analyzes the constitution of school writing as an object of research in scholarly investigations. The material analyzed was produced in graduate programs in Brazilian universities. The semantic foundations of discourses about Portuguese language education that were constituted in the 1980 s were observed. The research undertaken considered the textual organization of writing, produced in the teaching context, as a function of oppositions resulting from linguistic and or social differences. These differences are represented by a counterpoint between facts of orality and facts of writing. The characteristics of the texts produced in school are the result, on one hand, of the students not having knowledge about the writing modality, and on the other, that the conditions for production of text in the school are not authentic. In contrasting the elements associated to conditions inside and outside the school, factors of textuality are positioned as discursive indexes for the researcher when using school writing as an object of analysis.
\end{abstract}

Keywords: Language and Education. Writing. Discourse Analysis.
L'oralité, I'écriture et les conditions de production de textes à l'école: la constituion de l'ecriture scolaire comme objet des investigations academiques

\section{Résumé}

Ce travail thématise le processus de constitution de l'écriture scolaire en objet des investigations académiques. Le matériel d'analyse à été produit dans les programmes d'études supérieures dans les universités brésiliennes. Nous avons observé les bases sémantiques des discours sur l'enseignement de la Langue Portugaise constitués dans les années 80 du XXème siècle. Les travails de recherche développés en ce moment sont caractérisés pour considérer l'organisation textuel de l'écrit, produit dans le contexte de l'enseignement, en fonction des oppositions résultantes des différences linguistiques et/ou sociales. Telles différence sont représentées par la contra-position entre les faits de l'oralité et les faits de l'écriture. Les caractéristiques des textes produits à l'école se doivent, par une coté, des élèves n'ayant pas la connaissance sur la modalité de l'écriture, et par autre, des conditions de production de texte à l'école n'être pas authentiques. Dans le traitement en contraste avec les éléments associés aux conditions internes et aux conditions externes à l'école, les facteurs de textualité sont positionnés comme des index discursifs pour le chercheur dans son travail de constitution de l'écriture scolaire comme objet d'analyse.

Mots-clés: Langage et Éducation. Écriture. Analyse du Discours. 
